\section{Mathematical Vanity Plates}

\section{Donald E. KnUth}

This column is a place for those bits of contagious

mathematics that travel from person to person in the

community, because they are so elegant, surprising, or

appealing that one has an urge to pass them on.

Contributions are most welcome.

Extracted from the author's book Selected Papers on Fun and Games (2010) CSLI Publications, Stanford.

T

his story began in the spring of 1967 when I made a visit to Madison, Wisconsin, in order to give a lecture at the university. I was driving near the campus on a fine, sunny day. There was moderate traffic, and when a red light stopped me I happened to glance at the license plate of the car ahead. My jaw dropped-wow! It said "H65.536". I can still picture that plate in my mind, as plain as day, although more than forty years have passed; in fact, with modern software, I now can recreate its exact appearance:

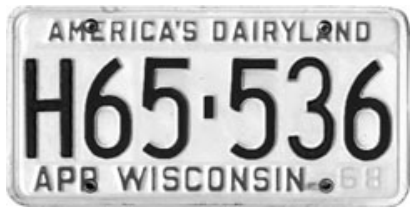

I started to jump out of my car, thinking that I might approach the driver to ask him if he knew what a fantastic license number he owned. But the light turned green; he

\footnotetext{
$>$ Please send all submissions to the Mathematical

Entertainments Editor, Ravi Vakil, Stanford University,

Department of Mathematics, Bldg. 380, Stanford,

CA 94305-2125, USA

e-mail: vakil@math.stanford.edu
}

drove away and I was unable to follow. I'll never know if he was aware that the state had assigned one of the most important numbers in mathematics to his car. How I envied him! Indeed, 65536 is not just an ordinary power of 2, and not simply the order of the multiplicative group in the Galois field of the largest known Fermat prime. It is

$$
2^{2^{2^{2}}}=2^{2^{2^{2^{0}}}}
$$

a number of huge importance in computer algorithms. Already in 1967 I had become a big fan of this number, and my appreciation has continued to grow as I continue to learn more.

\section{The OId Rules}

In those days each state of the USA required its drivers to purchase new license plates with new license numbers every few years, assigning the values in sequence. Thus your chance of getting any particular number $n$ was at most $1 / n$. People began to covet the small numbers-not because small numbers are mathematically interesting (which they are), but because small numbers are easy to remember. Small numbers also connote rank: The governor was number 1. The New York Times reported in 1959 [39] that

Low-numbered "vanity" plates have had a long and distinguished history in the automobile business. They have traditionally been obtained by politicians for their friends and campaign contributors. They have long been doggedly sought after by celebrities, egomaniacs and men who have everything. Last year about 69,000 New Yorkers paid $\$ 5$ extra for special low-numbered plates.

About 5 million automobiles were registered in New York state at that time; New York plates contained one or two letters to encode a county, together with a serial number.

Clever people didn't actually have to settle for a random number on their licenses, however. It was perfectly legal in many states, including New York and California, to get your plates in a remote county, far from where you lived. During a vacation to a sparsely populated area, you could drop in to the local office and obtain decent numbers without much competition. Furthermore, your initials might well be available in some rural county.

My father-in-law, who lived at 525 Summit Street in the medium-sized city of Fostoria, Ohio, was able to drive Ohio plates reading $525 \mathrm{~S}$ (his address) ever since the 1950s, because he was a friend of the local people who were in charge of auto registration.

Beginning in 1967, Wisconsin motorists could obtain plates of the forms A9, A99, A999, A9999, or AA999 by paying a surcharge, where $A$ denotes any letter and 9 
denotes any digit. Thus a person could pay to have G256, say, but not H65536.

I like to imagine that the man who acquired the plate I saw in Madison had obtained it on a day when he knew that the 65,500 s were being distributed. By carefully trading places with people behind him in line, he could then have seized the opportunity to acquire the license number of his dreams. Wisconsonites are friendly folks who would have been quite willing to accommodate such a whim-unless of course two mathematicians had been in the same line.

Every state in the USA has its own esoteric rules about license tags, except in one respect: All plates made since 1956 or so have the same size, $6^{\prime \prime} \times 12^{\prime \prime}$, so that automobile manufacturers know how much space to allocate for plate display on their cars.

When California adopted the standard size, it had to rethink the format of license numbers because the existing plates were somewhat larger. The old 'digit-letter-digitdigit-digit-digit-digit' style was capable of distinguishing 26,000,000 vehicles; for example, a license such as

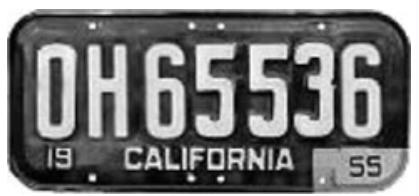

would be typical. But a maximum of six characters was desirable on the new plates, and California had more than 5.5 million registered cars. So the authorities introduced a new tagging scheme in which all passenger cars were identified

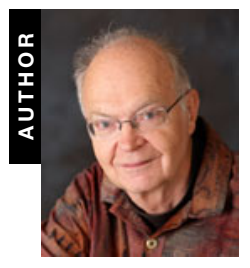

DONALD E. KNUTH is Professer Emeritus of The Art of Computer Programming at Stanford University, where he supervised the Ph.D. dissertations of 28 students since becoming a professor in 1968. He is the author of numerous books, including $4+\varepsilon$ volumes (so far) of The Art of Computer Programming, five volumes of Computers \& Typesetting, 1/3 volume of Concrete Mathematics, eight volumes of selected papers, and a collection of nontechnical essays entitled 3:16 Bible Texts Illuminated. His software systems $\mathrm{T}_{\mathrm{E}} \mathrm{X}$ and METAFONT are extensively used for book publishing throughout the world.

Computer Science Department
Gates Building 4B
Stanford University
Stanford
CA 94305
USA
http://www.cs-faculty.stanford.edu/ knuth

by three black letters followed by three black digits, on a yellow base, potentially allowing $230^{3}=12,167,000 \mathrm{com}-$ binations. (The letters I, $\mathrm{O}$, and $\mathrm{Q}$ were excluded.) These plates were distributed in batches of 1000 to district offices; thus you could easily identify where any given license had been obtained, by knowing local letter codes.

By 1963 it was time for new plates, and all Californians got new numbers again. The new scheme featured three yellow letters followed by three yellow digits, on a black base; my wife and I received

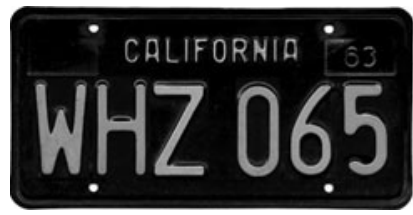

(meaning "Whiz by at 65 miles per hour"-the legal speed limit.) I didn't realize until later that, with this plate, we already owned three of the six characters in H65536. Notice that if I had been just 66 places earlier in the queue, my car would have been repeatedly asking, "WHY 999"?

Late in 1962, a determined young man had driven from Los Angeles to the small town of Alturas in the rugged northeastern corner of California, where he stood in line for 42 hours, braving both cold and rain to win the ultimate prize: California license AAA 000, the first of the new series [1]. I remember seeing him interviewed on television when he substituted this trophy for his former plate (which was WWW 333).

\section{Three-Letter Words}

The 1963 licenses began to allow the letter Q as well as the vowels $I$ and $O$, in the first and second positions, thus forming many new three-letter combinations with familiar connotations. Back in those days LOL didn't make anybody laugh; but the license ONE 234 was quickly spotted on a black Corvette. Staunch Democrats refused to accept GOP, but HIS and HER plates became popular with two-car families.

More serious, however, were three-letter combinations that were patently offensive, like (censored), (censored), (censored), and (censored). California's license czars had foreseen this problem already in 1955, when they asked Prof. Emeneau of the linguistics department at UC Berkeley to find all of the unsuitable words in the set $\{\text { A, B , C, D, E, F, G, H, J, K, L, M, N, P, R, S, T, U, V, W, X, Y, Z }\}^{3}$. He and his helpers "came up with 152 no-nos," including the word YES [27]. California's Department of Motor Vehicles (DMV) has always disallowed CHP (California Highway Patrol) and CIA (Central Intelligence Agency) on license plates; but DMV is OK. Perhaps they don't know that DMV stands for Deutsche Mathematiker-Vereinigung.

\section{Four-Letter Words}

American license plates rarely contained more than two letters during the first half of the 20th century. The reason may have been that license numbers were regarded as, well, numbers. Or perhaps officials realized that the 
possibilities for mischief grow exponentially as the number of letters increases. At any rate, motorists continued to want more and more varieties of personalized license tags, until finally the concept of vanity plates has broadened: Instead of simply having small numbers and/or our own initials, we're now free to express ourselves in any tasteful way.

Seeds of this revolution were planted in 1937, when Connecticut motorists with a good driving record were allowed to get plates containing just their three initials. Four-letter combinations appeared in Connecticut during the 1940s [2]. New Hampshire issued vanity plates of up to five letters in 1957; and Vermont followed soon after, allowing letters and numbers to be mixed.

Several years went by before the idea of decorating automobiles with personal names began to evolve into the display of personal statements. For example, when vanity plates of up to five letters became available in the District of Columbia in 1964, people's first choices were the one-letter plates from A to Z; numbers 1, 2, 3 were pre-reserved for the mayor, deputy mayor, and city council chair. (I don't think 0 was permitted.) Five years later, Colman McCarthy [32] surveyed the 6000 choices that DC drivers had reserved during their first years of plate-naming freedom. He found that most motorists chose their initials or their first names, in order to make their cars look swanky. A second group, reacting against "faceless numbers sent by a faceless computer," wanted to be identified in a more personal way using nicknames; the B-names in this category were BABS, BABY, BALDY, BEBE, BIRDY, BOBO, BOOFY, BUBI, BUNNY, BUTCH, and BUZZ.

But the new folk art of devising witty licenses was also beginning to develop in DC: A man named Carl Levin got C-11 for himself and S-11 for his wife Sonia. A man named Ware had two cars, respectively AWARE and BWARE. A retired Navy captain's Buick sported the license AWOL, received as a gift when he stepped down as head of the Citizen's Association of Georgetown. Uplifting messages like FAITH, HOPE, LOVE, JOY, MERCY, PEACE (and PAX) were also in evidence. Although YES was forbidden in California, the District of Columbia had both YES and NO as well as OUI; also OH NO, SORRY, and OOPS. Somebody in the nation's capital had MONEY, and I imagine somebody else had POWER-but McCarthy didn't speak to that.

\section{California Vanities}

California embraced self-designed license plates in 1970, but with a new twist: Motorists paid $\$ 25$ for this privilege, and $\$ 10$ per year afterwards, all earmarked for a special fund to fight pollution; thus the plates became officially known as environmental plates. Up to six letters and/or numbers were permissible, plus an optional space. Among the first requests were PAID 4 , OREGON, TURTLE, WHYWAR, GRANNY, and 32 FORD. Initial applications were collected for 30 days so that the most popular choices could be awarded by lot; but afterwards the rule was to be strictly first-come, first-served. The most wanted words, among about 10,000 applications initially received, were PEACE, SMILE, JAGUAR, GEORGE, TBIRD, BOB, LAWYER, MARGIE, MORGAN, LARRY, SNOOPY, LOVE, in decreasing order of popularity.
By December, the number-one Christmas gift in southern California was a new license plate with a message like $\mathrm{HOHOHO}$ Or XMAS 70.

Californians purchased more than 65 thousand personalized plates during the first 1.5 years, thereby raising more than $\$ 1.5$ million for the environmental fund; about 1500 new requests were being processed each week. By 1977 the fund had received $\$ 18$ million, and a total of 423,213 plates had been issued before April 1979, although 55,523 of them had not been renewed. Narrower letters and numbers were adopted in 1979 so that the licenses could contain up to seven characters; thus many more choices became possible, and about 600 new applications began to be filed every day. The millionth environmental plate was produced in 1982, at which time about 750,000 were actually in circulation.

\section{A Complete List}

One of my cherished possessions is the official list [8] of all California environmental plates that were current on 21 July 1981, obtained from a friendly administrator in 1982 when I explained that I was a computer science professor interested in database research. Altogether 665,571 entries appear in this list, and I estimate via random sampling that about $40 \%$ of them have length 7 .

What a wealth of ingenuity exudes from almost every page of this list! For example, I wondered if anybody had wanted to put BONFIRE on his vanity plate; sure enough, there it was-together with BONFYR and BONFYRE, as well as FALO, FALO1, and FALO2.

To get an inkling of California's 836-page collection, vintage 1981, let's consider page 316, which contains 798 entries from HOWZEIT to HRNDEZ, including HOWZIT, HOW2WIN, HOXIE, HOY, HOYLES, HOZWIFE, HP, HPBMW, HPBOOKS, HPBOSS, HPBRDAY, HPENNY, HPNOSIS, HPOWER, HPTYHOP, HPYTRLS, HRAKA, HRBLOCK, HRBONUS, HRCULES, HRDCORE, HRDROCK, HRDRSR, HRDTOP, HRDWARE, HRD2GIT, HRD2PAS, HRD2PLZ, HRD24GT, HRGOD, HRH, HRIZON, HRLEQIN, HRMIONE, HRMMPH, HRMNIZE, HRNBLWR. (Spaces are suppressed here because they're ignored in the DMV's test for equality of names.)

One thing that's immediately clear is that people with the same idea have been forced to spell it in different ways. We find plates like PLEYBOY, JIGOLO, FORSAIL, STOLIN, JILLOPY, LAEMON, NOWHEY, and POETIQ; of course this is just poetic license.

All 24 letters of the Greek alphabet are present in [8] except for ZETA and XI, which are represented by ZETA 7 and XICHI. And they often occur with "subscripts": ALPHA0, ALPHA1,..., ALPHA8, as well as ALPHA01 and ALPHA99 (which I guess were chosen by statisticians or social scientists). Latin scholars have contributed ERGOSUM, ERGOIAM, and ERGOIGO. We find both PUBLISH and PERISH, as well as HANSEL and GRETEL, PEARL and OYSTER, GOLD and SILVER, DONNER and BLITZEN, etc.

Yet there also are surprising gaps: The English numerals ONE, THREE, FOUR, FIVE, SIX, SEVEN, EIGHT, NINE, TEN, ELEVEN are present and accounted for, but 
TWO and TWELVE are lacking. Nobody in 1981 had even thought of VEHICLE. There was neither YIN nor YANG. Music lovers had named their plates after HAYDN, MOZART, B8HOVEN, BRAHMS, and MAHLER; alsO BACH, BACHJS, JSBACH, JSBACH1, and PDQBACH. But not (yet) BERLIOZ, DVORAK, or MILHAUD. A Beethoven fan had selected OPUS 132. ADAGIO, ALLEGRO, ANDANTE, LARGO, and PRESTO? Yes. LENTO and VIVACE? No.

\section{Other States}

Vanity-plate fever has continued to spread until all 50 states of the USA have long since flowed with the stream; in fact, the last state to inaugurate "own-choice" licenses was West Virginia in 1982. But even today, Massachusetts requires all numbers to be preceded by letters; in that state you can say MITPHD or MIT69 but not MY69MG, and you must use at least two letters. Illinois is similar, but it insists on a space separating letters from numbers.

Statistics from all 50 states and the District of Columbia, based on the total number of registered motor vehicles in 2005 as well as the total number that were "vanitized" as of 2006 or 2007 , show that the current fraction of vanity plates in the USA was $9292843 / 242991747 \approx 3.8 \%$ at that time, with greatest penetration in Virginia $(1065217 / 6578773 \approx 16.2 \%)$ and least in Texas (97315/17347615 $\approx 0.6 \%)$. California ranked $22 \mathrm{nd}$, with a ratio of $1136772 / 32592000 \approx 3.5 \%$.

Thus vanity plates have clearly become thoroughly integrated into American pop culture. For a nice survey of vintage 1986 plates, see Eckler [13].

A complete list of current South Dakota vanity plates, containing 15,483 entries from 001 to ZZZZOOM, was posted on the Internet on 25 October 2009 [30], and it's interesting to compare it to the California list of 1981. The interval from page 316 of [8], discussed above, intersects the South Dakota data in only three cases: HPYDAYS, HPYTRLS, HRDROCK. There are 22 other South Dakota plates in the corresponding interval, including $\mathrm{HPBD} 2 \mathrm{ME}$, HPYGIRL, HRDLUCK, HRDLY, HRHOTRD, and HRMSWAY.

\section{The Challenge}

So how do mathematicians fit into this fast-growing trend? Dentists can advertise their specialty with "dental plates" such as DENTIST, 2TH DR, DRILLER, SMILE, MOLARS, CUSPID, GUMSAVR, NO DK, FLOSSEM, CROWNS. Physicists now sport licenses like PHYSICS, NUCLEON, DELTA S, GLAST, XRAY BMR, CY N TIST, E PLUS, and E MINUS [11]. And of course E COLI [8] belongs to a biologist.

If you, like me, don't already own a vanity plate, what would be your first choice? What's the briefest and best way to represent yourself to the world? If there's something that's uniquely you, there's a greater chance that it won't already be reserved.

Ideally your choice should bring a smile to people who see it. They'll think, "Aha! A person who loves mathematics!" Alternatively, you might choose something that will please and amaze specialists, although the masses won't get the point; that can still lead to teachable moments.

Many of the things we deal with as mathematicians involve words that are much too long: DIFFERENTIAL, MATHEMATICS, DETERMINANT, CONJUGATE, INTEGRATION,
COMPUTATION, LOGARITHM, PERMUTATION, ARITHMETIC, ALGORITHM, COUNTEREXAMPLE, etc., etc. There are some shorter terms like MATHS, ALGEBRA, SINE, COSINE, TANGENT, MATRIX, GROUP; but they're in [8], already claimed ages ago. What's left?

I remember discussing this question with my son, long ago when he was in elementary school and vanity plates were fairly new. I told him that, ha ha, our car should say VANITY. (I naïvely believed that this was an original thought.)

But he had a much better idea: How about letting the plate be entirely blank? At that very moment I realized that he was a budding mathematician, wise beyond his years. For indeed, what could be more vain, yet more rich in mathematical properties, than the empty set? This idea trumps even the governor's number 1 .

Unfortunately, though, the empty string is too short a word for state bureaucrats to understand. And even if they did issue a blank plate when you left the form blank, what do you think highway patrolmen would do when you drove by? Not everybody understands the empty set, alas.

On the other hand-surprise-I happened to spot 7 SPACES, on 8 August 2004. Aha, I learned, the empty plate does exist! (Moreover, 7 BLANKS is still available in California, as of 5 November 2009.)

\section{The Character Set}

Before we investigate the possibilities further, we need to know the ground rules, which differ from state to state.

The most important limitation is the total number of characters. Wyoming residents are expected to be most creative: They must express themselves in four symbols or less, in order to leave room for a county code and the famous bronco-buster logo. (Unfortunately, this state and some others have recently switched to "digital plate technology," produced by laser printing instead of embossing, with an atrocious font. It looks cheap, perhaps because it is. If I lived there I'm afraid I would choose the word UGLY until they reverted to the beautiful style of 2002.)

The maximum message length in Alaska, Connecticut, Hawaii, Kentucky, Maine, Massachusetts, Missouri, Oregon, Rhode Island, and Texas is 6. All other states have a limit of 7, except for New York, North Carolina, and West Virginia, where you can (gasp) go up to 8. Only in the latter three states can you claim GEOMETRY or TOPOLOGY.

What can those 4 or 6 or 7 or 8 characters be? All 26 uppercase letters from $\mathrm{A}$ to $\mathrm{Z}$ are legal, and New Mexico allows also $\tilde{\mathrm{N}}$. The digits 2 through 9 are obviously all OK too. But 1 is equivalent to $I$ in Louisiana and Minnesota; and 0 presents a really sticky problem.

Consider the following nineteen entries from [8]: $\mathrm{OO}, \mathrm{O} 0$; 000, 000, 000; 0000, 0000; 00000, 00000, 00000, 00000; 000000, 000000; 0000000, 0000000, 0000000, 0000000, 0000000,0000000 . There are 240 or 241 combinations of $\mathrm{O}$ and 0 that don't conflict with plates in the ordinary sequential series; by July of 1981, Californians had reserved those 19. (I'm not sure whether 0000000 would have been legal.) Such plates must have caused nightmares for police officers because they're so hard to distinguish. Therefore $\mathrm{O}$ and 0 have now become identical 
in California; also in Colorado, Louisiana, Minnesota, Nevada, North Carolina, Vermont, and Wisconsin. I don't know when this change was made, or if cars with visually ambiguous licenses are still on the road in California.

South Dakota still considers $\mathrm{O}$ and 0 to be distinct; I know this because [30] lists both 0000000 and 0000000 but no other combinations of length 7 . Massachusetts does too, because AUTO is taken but AUTO is not.

The most interesting variation between states, vanitywise, is the set of allowable delimiters or punctuation marks that can appear. My eyes popped in 1985 when I first saw New Hampshire plates containing + signs as well as - signs, opening up a whole new world of mathematical vanities. Complex analysts in the Granite State can adorn their cars with X+IY. (California now has + signs too; see below.) New Hampshire had previously used heavier, red-cross-like symbols on licenses specifically for ambulances; in 1974 they reserved $\mathrm{AMB}$ for ambulance plates, and eventually they made vanity pluses available for use by anybody [18].

Furthermore, New Hampshire drivers are able to use ampersands. Hence they can construct the wonderful formula $-\mathrm{X} \& \mathrm{X}$, which yields the least significant 1-bit, if any, in the binary representation of $x$ (see [26, Eq. 7.1.3-(37)]). I checked both X+IY and $-X \& X$ on New Hampshire's website in November 2009, and both of them were available. But $\mathrm{X} \&-\mathrm{X}$ was illegal, because consecutive punctuation marks are forbidden.

Most states allow only letters and digits. But a minus sign (or hyphen) is permissible in Alabama, Colorado, Delaware, Florida, Kentucky, Louisiana, Minnesota, Missouri, New Mexico, North Carolina, Oklahoma, Oregon, Pennsylvania, Virginia, and Washington, as well as New Hampshire. An ampersand is legal in Delaware, New Hampshire, North Carolina, North Dakota, South Carolina, and Virginia. You can use a dot in Colorado, Connecticut, Louisiana, and North Carolina. Apostrophes are OK in Missouri, New Mexico, and (again) North Carolina.

North Carolina, in fact, is Vanity Plate Heaven. We've seen that tarheels are able to enjoy up to 8 characters that include pluses (+), minuses ( - ), dots (.), and apostrophes ('); and in fact they can also have number signs (\#), question marks (?), dollar signs (\$), asterisks (*), slashes (/), equals signs (=), at signs (@), colons (:), double quotes ("), commas (, ), and exclamation points (!)! Unfortunately for mathematicians, the list stops there; parentheses, and the relational signs $<$ and $>$, aren't permitted. Unfortunately for $\mathrm{T}_{\mathrm{E}} \mathrm{X}$ users, backslashes and curly braces are lacking too.

But hey, $\$ 720=6 ! \$$ in this state. Calculus and physics teachers can have $\$ d x / d t \$$, etc. (All special characters are ignored when comparing two plates; thus 7206 and $d x d t$ would be indistinguishable from those punctuated examples, and so would \# 7+2 / 0-6 and dx/dt?, both of which happen to be presently available-subject to approval by the authorities.)

I wonder if a fallacious proposition such as $\$ 120=6$ ! \$ would also be acceptable to the North Carolina censors. Probably it would, thereby setting back education in the Southeast. Even worse, I fear that somebody will ask for BAD@MATH and be proud to display it. But let's not be pessimistic; North Carolina deserves applause for leaping way ahead of everybody else.

Besides ordinary punctuation, a few special characters are also available. New Mexico has an enchanting Zia Sun symbol, which their website illustrates with the example VAN ITY. New York offers a blob in the shape of its empire, which I won't illustrate here.

Since 1994, California has allowed a single delimiter to appear on vanity plates, taking the place of a letter or digit. There are four choices: Drivers can use either a plus sign or one of the unique symbols $\{\boldsymbol{v}, \boldsymbol{\star}, \boldsymbol{v}\}$. The senior co-editorin-chief of this journal could be CWLER D if he moved to California; Steve Smale could be $\Psi$ LE BODY. Both of these are currently up for grabs, as are X+IY, IVMATHS, and $L \star S P A C E$.

The rules for spaces (I mean blank spaces, not $L^{*}$ spaces) are too complicated to explain here. Suffice it to say that most states allow you to insert them in order to improve readability.

\section{Examples on the Road}

Let's look now at how some mathematicians and/or their friends have risen to the occasion by meeting these constraints.

Cathy Seeley, who was president of the National Council of Teachers of Mathematics (NCTM) from 2004 to 2006, likes her license plate so much that she included it in an illustrated lecture that I found on the Internet:

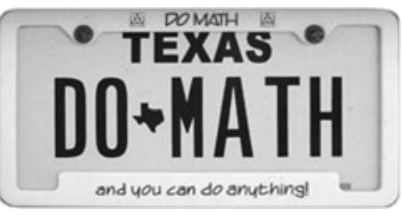

Her plate sits in a holder that was in fact produced by the NCTM, saying "Do math and you can do anything!" (I'd amend that to "Do math and learn to write, and you can do anything"-but my version wouldn't fit the frame.)

She told me about two other nice examples: Ed Rathmell, a math professor at the University of Northern Iowa who does a lot of work with education, is MATH ED. And Gail Englert, a middle-school math teacher in Norfolk, Virginia, has IEDUK8M, with a nice play on ' $\mathrm{K}-8$ ' in education

David Eisenbud, who was president of the American Mathematical Society (AMS) during 2003 and 2004, received an appropriate plate from his wife shortly after he became director of the Mathematical Sciences Research Institute in 1997:

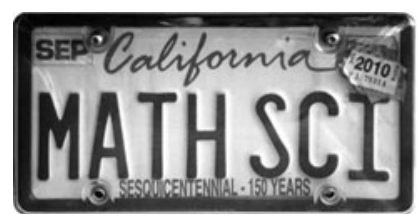

Incidentally, when I spotted the California plate I AM PAMS on 2 January 2001, I realized that it did not refer to 
Proceedings of the American Mathematical Society-because Clifford J. Earle, Jr. was at Cornell.

Vanity plates that name the basic words of our discipline are more difficult to come by, because more people try to reserve them. Victor Miller has been doubly successful in this regard, because he not only owned New York ALGEBRA in 1978, he purchased New Jersey ALGEBRA in 1993! He still drives it:

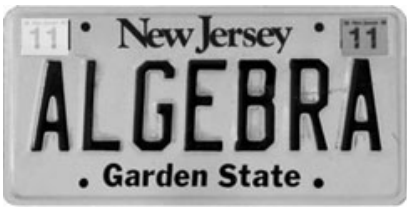

Dave Bayer is another lucky mathematician who obtained the plate of his dreams, perfectly suited to his work on geometric invariants [4]:

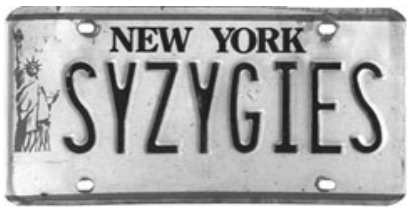

He is evidently not alone, because the California list from 1981 [8] already contained SYZYGY, SYZYGY1, SYZYGY2, SYZYGY3, SYZYGYS, and SYZYGYX, as well as SYZ WIZ.

The key wOrds NUMBER, THEORY, and THEOREM were also unavailable to Californians who sought new vanity plates in 1981. But eventually two of them came back into play: Fan Chung and her husband Ron Graham (the AMS president in 1993 and 1994) now have personal plates, acquired in 1999, that are amazingly appropriate when parked side by side:

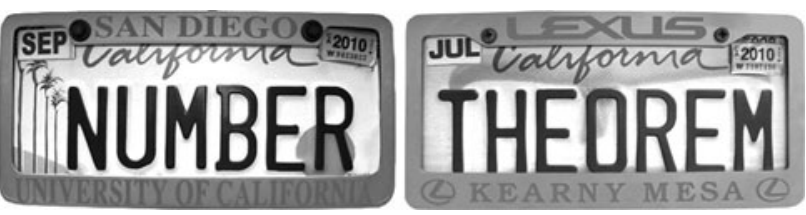

The existence of Ron's plate implies that THEOREM is once again unavailable; so I used the DMV website to try for LEMMA. It, too, is currently taken, and so is DILEMMA. So are MATRIX and VECTOR; but not TENSOR. (According to [30], NUMBER, THEORY, THEOREM, LEMMA, DILEMMA, MATRIX, VECTOR, and TENSOR are all presently available in South Dakota, as are DO MATH, MATH SCI, ALGEBRA, and SYZYGY. This observation doesn't prove that South Dakotans are anti-mathematics; indeed, [30] does list MATH ROX, NUMBERS, and NUMB3RS.)

Fan and Ron also share a recreational vehicle with a tag that commemorates their joint work on quasi-random graphs and other quasi-random structures [9]:

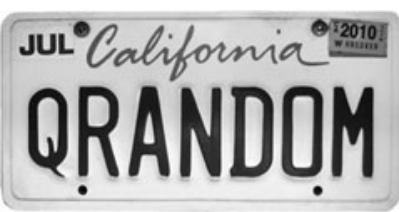

(This license plate incidentally illustrates the unfortunate fact that California has never figured out how to make a decent-looking letter Q. From a typographic standpoint, Wisconsin and other states would actually be better places to advertise QRANDOM research.)

Ron tells me that he often sees $2+2 \mathrm{R} 4$ in the parking lot of the math building at UCSD; another one is S CUBED. At a higher level he also encounters RC FLOW, representing Ricci flow-the key idea with which Grisha Perelman resolved Poincaré's conjecture [36].

Andy Magid has said [31] that he's the only licensed Galois theorist in Oklahoma, because he drives GALOIS. "Most people who read or have to record my car tag, such as tow truck operators or highway patrol officers, do so without comment or even accurate pronunciation. But on occasion it does provoke welcome conversation."

What about the names of other famous mathematicians? I checked a few, to see what California drivers have selected, and got a shock:

\begin{tabular}{lll}
\hline name & taken in 1981? & taken in 2009? \\
\hline FERMAT & no & yes \\
EULER & yes & no \\
LAPLACE & yes & yes \\
FOURIER & no & yes \\
GAUSS & no & yes \\
GALOIS & no & no \\
HILBERT & no & yes \\
\hline
\end{tabular}

Alas-my personal hero, Leonhard Euler, has waned in popularity out west. (But David Robbins did have New Jersey EULER for many years.)

The license plate BIG OH has been spotted in New York, and it's also present in California. I love that notation [24]. At present New Yorkers, like me, are less enthusiastic about LITTLE OH.

My colleague Ingram Olkin in Stanford's Department of Statistics received STAT PRO as a gift from his children about ten years ago. His daughter Julia now has the California plate SOLV4X; she really wanted SOLVE4X, but it was already taken in 1981 [8].

California's 1981 list had OPTIMUM, MINIMUM, and MAXIMUM; also OPTIMAL and MINIMAL but not yet MAXIMAL. It included both MINMAX and MINIMAX, as well as MAXIMIN and-my favorite-MAXIMOM. There was a $\mathrm{Z}$ AXIS on the road, but no X AXIS or Y AXIS. Somebody had DY DX; another had DU DS but without the space.

Fifty-two of the California environmental plates in 1981 began with MATH. Some of them, like MATHER, MATHEW, and MATHIS, were surnames that aren't relevant to our discussion; MATHIEU may, however, have belonged to a group theorist. Noteworthy are MATHBIZ, MATHMAN, MATHPRO, MATHS, 


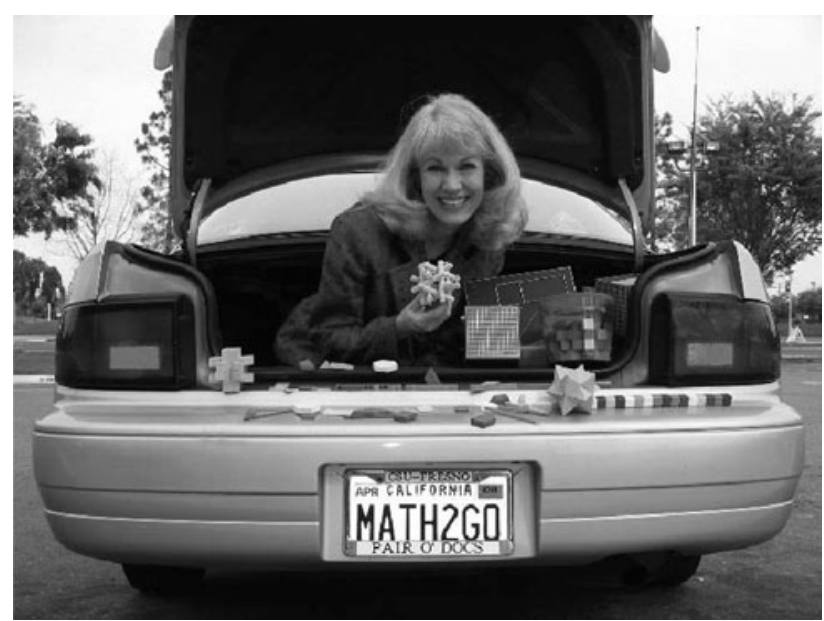

Figure I. NCTM prizewinner Carol Bohlin.

MATHWIZ, and MATH4U. I fear that MATHANX was supposed to suggest anxiety rather than thank-you-dear-ma; and MATHOS was perhaps a feminine form of PATHOS.

A light-hearted competition for the best vanity plate with a mathematical theme was organized by the NCTM at the beginning of 2005, and prizes were awarded at their meeting in April of that year. First place went to a "pair o' docs" named Carol and Roy Bohlin, who teach at Fresno State University and always carry a trunkful of material for the math classes and workshops that they teach (see Figure 1).

\section{Small Integers}

Of course license plates have traditionally featured numbers rather than letters, and nothing can be more mathematical than numbers. Therefore mathematical vanity plates often involve carefully selected numbers.

Let's start at the beginning with 0 . We've already noted that California's database from 1981 [8] had many combinations of 0 and $O$. It also included DOUBLE0, DOUBLEO, DBL00; in fact, somebody even claimed OXO EQ 1 ! There was a vote for 0 ONUKES. My favorite from [8] in this category, however, is $00 \mathrm{MPH}$ - a plate that is not only pronounceable, it is semantically equivalent to STOPPED, if you think about it.

Moving up, the use of 1 as a cardinal number was quite common, as in 1 EGO FIX, 1 FOW VEY, 1 HONKER, 1 LITER, 1 MOMENT. The ordinal 1 appeared too, in 1ST AID, 1ST ALTO, 1ST HALF, 1ST LAP, 1ST N 10, 1ST VIOL. The plate 1 F100 may have denoted a hypergeometric function; but I don't know the significance of 1DELTA1, 1OMEGA1, 1SIGMA1 (all found in [8]).

Laurence C. Brevard tells the following story (see Figure 2): I got 1 OR 0 in Texas in 1982 but the picture shows the 1984 plate. Back then you got new plates every year instead of the stickers they use now. . . . After I moved to Oregon in 2001 I got the same plate "number" there. People consistently thought the OR stood for Oregon. Sigh... Someone else has this plate in California! I also have had the domain 1or0.com since 1998.

May I suggest ORBITS? (Sorry.) Bill Ragsdale sent me a picture of the license 100100 which he spotted
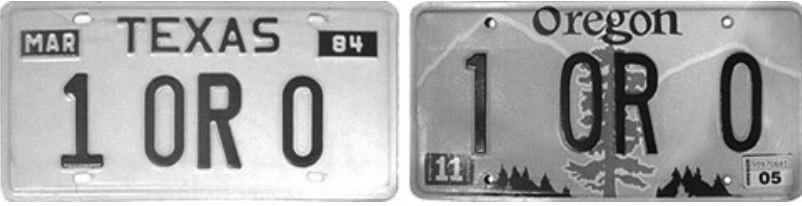

Figure 2. Shades of Leibniz and Boole.

during a trip to China in 1984 . He theorizes that "China is moving to binary license plates due to the difficulty of their character set."

The website of Utah's Division of Motor Vehicles [40] provides helpful examples of personalized plates, including $2 \mathrm{XX} 3 \mathrm{XY}$, which certainly looks mathematical. Upon further inspection, however, this one actually turns out to be genomical: The driver has two girls and three boys.

Indeed, I've rarely seen license plates that celebrate the beautiful mathematical properties of small integers. Why haven't people chosen messages such as 0 IS NONE, 0 IS LOG1, 1 IS UNIT, 2 IS EVEN, 3D WORLD, 4 COLORS, 5 IS F5, PERFECT 6, 7 FRIEZES, 8 IS CUBE, or PAPPUS 9? A large territory remains to be explored. (In [8] I do find 1 IS ALL and 10ISBUF; but the latter surely was chosen by a tennis buff.)

François Le Lionnais wrote a classic book [28] that is filled with good reasons to like particular numbers, and David Wells has written a similar but more elementary sequel [41]. (See also De Koninck [12].) There's a well-known proof by induction that all nonnegative integers are interesting; for if this statement were false, the smallest noninteresting number would certainly be quite interesting. QED.

Following this reasoning we can conclude that the number 62 is interesting, because it's the smallest integer that appears neither in [28] nor in [41]. The more recent book [12] lists only prosaic facts about 62

But John Conway has discovered that 62 also has a far more interesting property, namely that it's the least $n$ such that no number is exactly $n$ times the sum of its digits. (See [38], sequence A003635.) We could make a vanity plate from that fact: WHATS 62 .

On the other hand, Gordon Garb told me a cautionary tale. After having been excited and inspired by a reference to a paper by Li and Yorke entitled "Period three implies chaos" [29], he once decided to acquire the California vanity plate PERIOD 3. Unfortunately, his choice didn't turn out to be as cool as he had hoped:

In the years that I had it on my vehicle, nobody ever got the Chaos reference. I explained it many times when friends asked, but what fun is an inside joke if you always have to explain it? My future wife told me years later that she just assumed I was a hockey fan. ... I replaced it with a vanity plate that simply has my typical login name.

\section{Bond; James Bond}

What is the most-wanted three-digit number on a vanity plate? The winner, hands down, is 007 . Uncountably many motorists have apparently dreamed of masquerading as Ian Fleming's immortal character James Bond. In the 1981 list [8], for example, one can find AGNT007, BONDOO7, BOND 
007, DBLOH7, DBL07, DOUBL07, DUBLE07, D007, JAMES07, JBOND, JB007, JMSBOND, JMSB007, J007, OHOHSVN, OHOH7, O07, OO7BOND, OO7LIVZ, OOSEVEN, OOVII, 007, 007LIVS, 00SVN, and probably more that I've missed. (The choice 007 was not allowed; nobody had yet taken 007.)

In 1966, Sol Golomb created Bond's illustrious binary cousin, Secret Agent 00111, when he introduced the concept of run-length encoding for sequences of bits [16]. Several of the exciting and bizarre exploits of this intrepid information trafficker were revealed later, in an introductory textbook [17]. Agent 00111 either remained undercover in 1981 or failed to own a California vehicle at that time; but he or she is now driving somewhere in the state, and also in Florida.

\section{Real Numbers}

Mathematics doesn't limit itself to whole numbers, of course; many others are out there, including SURREAL ones [8, 22].

What do you think is the first noninteger number that most people think of? You're right: It's $\pi$.

To verify this hypothesis, I looked up the license plates that are currently available in Florida, Michigan, Nevada, and North Carolina, which are among the few states that allow motorists to choose plates that contain seven digits and no letters. In each case the combinations 3141592 and 3141593 have already been taken, but 3141591 and 3141594 have not. (Recall that $\pi \approx 3.1415926535897932$.) This cannot be just a coincidence. In North Carolina, which allows up to eight digits, I checked for 31415926 and 31415927 as well, but those plates are still available. The $\pi$-fanciers of that state have most likely taken advantage of their typographic freedom by selecting plates with the decimal point included: 3.141592 and 3.141593.

Arizona motorists have currently claimed 314, 3141 , 31415,314159 , and 3141592, but not 3141593. Have they perhaps been basing their choices on the successive version numbers of $\mathrm{T}_{\mathrm{E}} \mathrm{X}$ [23]?

Although California doesn't permit plates that are entirely numeric, the 1981 list [8] does include QT314, QT31415, and QT31416, as well as PI R SQ and PI R2.

The people have spoken: $\pi$ wins!

Figure 3 is a historic photo from 1987 that shows four people who have made significant contributions to the high-precision evaluation of $\pi$ : Gene Salamin, Yasumasa Kanada, David Bailey, and Bill Gosper. They're gathered around Bailey's appropriately numbered car. At that time Kanada held the world record, having recently computed $\pi$ to $134,214,700$ decimal places. He had helped with the first calculation that exceeded 2 million places, in 1981, but that record didn't last long; Gosper had topped 17 million places in 1985, using some ideas of Salamin, and Bailey had surpassed 29 million in 1986, before Kanada got back in the lead [3]. More than two further decades of continued progress have led to the astonishing present record of nearly 2.7 trillion decimal places, announced on 31 December 2009 [5]. This major feat was achieved by Fabrice Bellard on a personal desktop computer after 131 days of calculation.

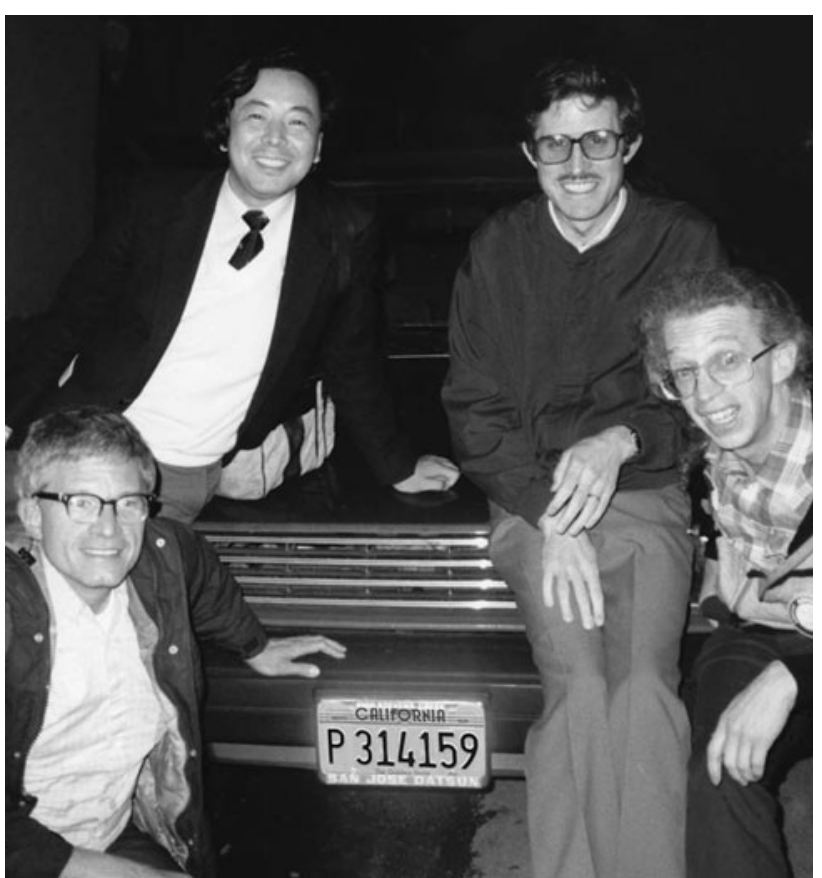

Figure 3. Four mathematicians with a nonrandom license plate.

David Bailey's current license shows $\pi$ in a less familiar guise:

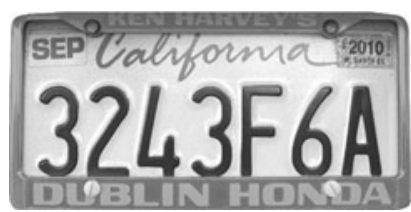

Hexadecimal notation, which makes $\pi$ equal to $(3.243 \mathrm{~F} 6 \mathrm{~A} 8885 \mathrm{~A} 3 \ldots)_{16}$, nicely meets California's stipulation that all license plates must contain letters. And it's also especially appropriate for Bailey, who helped to discover the remarkable formula

$$
\pi=\sum_{k=0}^{\infty} \frac{1}{16^{k}}\left(\frac{4}{8 k+1}-\frac{2}{8 k+4}-\frac{1}{8 k+5}-\frac{1}{8 k+6}\right),
$$

by which the $n$th hexadecimal digit of $\pi$ can be efficiently computed without evaluating the previous $n-1$ [3].

Martin Davis currently drives around Berkeley with the vanity plate E I PYE. (He is also martin@eipye.com.) That's a very nice formula; but I think my own preference would be SQRT 2PI, which happens to be currently available if I decide to go for it.

While writing this essay I tried to find other familiar constants $(\sqrt{2}, e, \phi, \gamma)$ by querying the appropriate websites in Arizona, Florida, Michigan, Nevada, and North Carolina. But I encountered only a few hits: Arizona drivers have reserved 271828, 1618PHI, and 1618033; North Carolina drivers have reserved $1.414214,2.718282$, and 1.618034; otherwise nothing. From this limited sample it appears that fans of Euler's constant have not yet arisen to promote their cause, and that rounding is preferred in the East but not the West. A rich vein of important numbers remains to be claimed, vanitywise. 
Sometimes people obtain mathematically significant license plates purely by accident, without making a personal selection. A striking example of this phenomenon is the case of Michel Goemans, who received the following innocuous-looking plate from the Massachusetts Registry of Motor Vehicles when he and his wife purchased a Subaru at the beginning of September 1993:

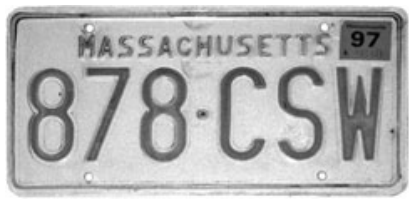

Two weeks later, Michel got together with his former student David Williamson, and they suddenly realized how to solve a problem that they had been working on for some years: to get good approximations for maximum cut and satisfiability problems by exploiting semidefinite programming. Lo and behold, their new method-which led to a famous, award-winning paper [15] -yielded the approximation factor .878 ! There it was, right on the license, with C, S, and $\mathrm{W}$ standing respectively for cut, satisfiability, and Williamson.

\section{Large Numbers}

Let's return now to the scenario we began with, a license plate that bore the desirable number 65536. Mathematicians have traditionally befriended numbers that are much smaller than this, because smaller numbers tend to have more interesting properties. (Or perhaps because smaller numbers have properties that are easier to discover without computer assistance.) Le Lionnais considered this situation in his postlude to [28], saying "Tous les nombres sont remarquables, mais peu ont été remarqués." His book discusses 219 integers between $2^{0}$ and $2^{20}$, having a total of 574 "properties," with the distribution of $k$-bit numbers that is shown in Figure 4 for $1 \leq k \leq 20$. In this illustration the black bars stand for numbers and the gray bars stand for properties; for example, when $k=1$ the sole number is 1 and he mentions 14 of its properties.

The sole number listed for $k=20$ is 604800 , the number of elements in the Hall-Janko group (the fifth sporadic group); this number also has the property that some of its divisors yield an interesting "congruence cover." A congruence cover is a set of integer pairs $\left(a_{1}, d_{1}\right), \ldots,\left(a_{s}, d_{s}\right)$ with $d_{1}<\ldots<d_{s}$ such that every integer is congruent to $a_{k}$

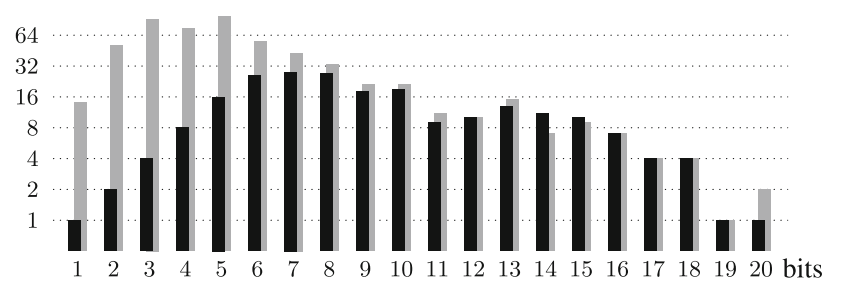

Figure 4. Remarkable numbers (black) and remarkable properties (gray) in [28]. (modulo $d_{k}$ ) for some $k$. For example, the simplest congruence cover [14] is

$$
\{(0,2),(0,3),(1,4),(1,6),(11,12)\} .
$$

Robert Churchhouse [10] found a congruence cover for which $d_{1}=9, d_{s}=d_{124}=2700$, and $\operatorname{lcm}\left(d_{1}, \ldots, d_{s}\right)=$ 604800; when Le Lionnais wrote [28], Churchhouse's example had the largest known value of $d_{1}$. (Erdös had conjectured that $d_{1}$ could be arbitrarily large. His conjecture remains open, and carries a $\$ 1000$ reward for the solver. A cover with $d_{1}=40$ and $s \approx 10^{50}$ has recently been found [33].)

What other properties does 604800 have, besides the two that were featured by Le Lionnais? For this question mathematicians can now turn to Neil Sloane's wonderful On-Line Encyclopedia of Integer Sequences [38], which tells us for example (in sequence A053401) that there are 604800 seconds in a week. Sequence A001715 of the OEIS reminds us that $604800=10 ! / 3$ !; from this fact we can conclude, with a hint from A091478, that exactly 604800 simple graphs on 5 labeled vertices have 7 labeled edges. Furthermore we learn from sequences A055981, A058295, $\mathrm{A} 060593$, and A080497 that 604800 is the number of ways to write an 11-cycle as the product of two 11-cycles on the same elements [6], and that 604800 can not only be expressed as 5 ! 7 ! and as 12 !/d(12!) but also as

$$
\begin{aligned}
& (1 \times 2 \times 3 \times 4 \times 5 \times 6 \times 7 \times 8 \times 9 \times 10 \times 11) \\
& \quad /(1+2+3+4+5+6+7+8+9+10+11)
\end{aligned}
$$

and-via prime numbers-as

$$
(17-2)(17-3)(17-5)(17-7)(17-11)(17-13) .
$$

Altogether the number 604800 appears explicitly in 78 sequences of the current OEIS list, so it possesses 78 "OEIS properties." I can well imagine that Marshall Hall, who was my Ph.D. advisor long ago, would have been delighted to drive an automobile whose license plates bore the number 604800 .

These considerations beg us to ask, "What numbers greater than, say, 10000, have the most OEIS properties?" I posed this question to Sloane in 2001, and he told me how to answer it by downloading a stripped version of the database. The current champion numbers, by this criterion, are shown in Table 1.

Several conclusions can readily be drawn from this table. First, we notice that the magic number 65536 of my Madison experience is right up there, nearly tied for the lead. Second, almost all of these property-rich numbers are round in G. H. Hardy's sense: They are "the product of a considerable number of comparatively small factors" [20, page 48]. The only exceptions are 10001 and 11111, which are oriented to radix-10 notation. Indeed, all of the champions other than 10001 and 11111 are powers of 2, 3, 5, 6, 7, 10, or 11, except for 8!, 9!, and 10080 (which is twice 7!).

Table 1 ranks a number $n$ by counting only the sequences in which the OEIS database lists $n$ explicitly; it doesn't count all the sequences to which $n$ actually belongs. For example, A005843 is the sequence of even numbers, which explicitly lists only $0,2,4,6, \ldots, 120$; a number like 


\begin{tabular}{llll}
\hline \multicolumn{4}{l}{ Table 1. Numbers } \\
\hline value & props & with the most OEIS properties & \\
\hline 16384 & 646 & value & props \\
65536 & 638 & 46656 & 321 \\
32768 & 621 & 1000000 & 316 \\
262144 & 577 & 362880 & 305 \\
40320 & 508 & 10080 & 301 \\
15625 & 415 & 100000 & 291 \\
1048576 & 387 & 531441 & 288 \\
19683 & 365 & 14641 & 288 \\
16777216 & 360 & 10001 & 282 \\
2097152 & 348 & 524288 & 278 \\
59049 & 337 & 4194304 & 258 \\
131072 & 328 & 11111 & 255 \\
\hline
\end{tabular}

604800 is even but doesn't have the OEIS property of evenness. Being near the beginning of a sequence seems to make membership stronger, because the fact that 2 is even is noteworthy for 2 but the fact that 120 is even is basically "duh" for 120.

Therefore I tried another experiment in which the successive values of each OEIS sequence are assigned weights $1,1 / 2,1 / 4,1 / 8, \ldots$. Table 2 shows the integers that currently are most important by this criterion, and again 65536 ranks near the top. Here the tendency to prefer "roundness" is even more pronounced than before: Every number in Table 2, with the exception of 10001, is a power of 2, 3, $5,6,7$, or 10 .

I'm willing to admit that such numbers are important. Yet somehow the criteria used to generate Tables 1 and 2 leave me dissatisfied from the standpoint of license-plate desirability. One reason is that many of the OEIS sequences are not really very interesting at all, propertywise. For instance, the HallJanko number 604800 occurs near the beginning of A002677, but only because it's the denominator of an obscure constant called $M_{3}^{\prime 11}$ [37]. Frankly, I couldn't care less.

Numbers are often in fact especially interesting when they're at the end of a sequence, not the beginning. For example, 65537 is interesting because it's the largest known Fermat prime (A092506, A019434); 43112609 is interesting because it's the binary length of the largest prime number ever discovered, (11...1) $)_{2}$ [42]. (Fans of 43112609 can't use

\begin{tabular}{llll}
\hline Table 2. Numbers $>\mathbf{1 0 0 0 0}$ with the heaviest & OEIS properties & \\
\hline value & weight & value & weight \\
\hline 262144 & 27.9 & 390625 & 13.5 \\
16777216 & 27.6 & 68719476736 & 13.5 \\
65536 & 22.5 & 4194304 & 13.2 \\
531441 & 21.5 & 78125 & 13.2 \\
59049 & 20.8 & 16807 & 13.1 \\
19683 & 20.4 & 823543 & 12.9 \\
15625 & 19.8 & 177147 & 12.6 \\
1048576 & 18.6 & 117649 & 12.1 \\
16384 & 18.5 & 10001 & 11.8 \\
46656 & 18.2 & 9765625 & 11.6 \\
387420489 & 15.1 & 100000 & 11.6 \\
32768 & 15.1 & 2097152 & 11.3 \\
\hline
\end{tabular}

it on a license plate, however, except in North Carolina, because it is eight digits long.) I imagine that Richard Brent's favorite number is 1568705 , which is currently the last element of A064411, because he was surprised to discover it in the continued fraction for $e^{\gamma}$ [7]; remarkably, this 7-digit value arises rather early on, as the 4294th partial quotient of a number that probably isn't rational.

In my own case, if I had had a chance to choose my favorite 5-digit number to put on a license plate in 1969 , shortly after I had seen the plate in Madison, my choice would not have been 65536; I would definitely have chosen 12509 instead. Why? Because I had just completed extensive calculations leading to the conclusion that 12509 is the smallest $n$ such that $l(n)<l^{*}(n)$, where $l(n)$ is the length of the shortest addition chain for $n$ and $l^{*}(n)$ is the length of the shortest "star chain" (see [21], \$4.6.3). Before I had done these computations, such integers were known to exist because of a theorem due to W. Hansen [19], but the smallest example that could be based on his theorem was the gigantic value $n=2^{6103}+\left(2^{1016}+1\right)\left(2^{2032}+1\right)$. At once 12509 became my favorite 5-digit number.

I bet Neill Clift's favorite 8-digit number is 30958077 , because he discovered in 2007 that it's the least $n$ such that $l(n)=l(2 n)=l(4 n)$.

Incidentally, the largest integer in the California list [8] was 9 GOOGOL, namely $9 \times 10^{100}$. But it was trumped by ALEPHO and ALEPH1.

\section{Computer Science}

In my day job I profess to be a computer scientist, not a mathematician, although there is definitely a soft spot for mathematics in my heart. Thus my closest colleagues have a computer-oriented rather than math-oriented perspective in their predilections for personalized plates. For example, Gio Wiederhold drives D8ABASE. Vaughan Pratt chose DUELITY, because his work makes considerable use of DUALITY (which was already taken when he tried to get it) and because his duality also applies to games.

The most famous license plate from Stanford's Computer Science Department is undoubtedly the one by which the late Gene Golub aptly described himself:

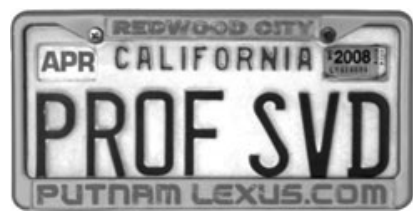

This much-photographed plate, now his epitaph, highlights the leading roles that he played with respect to the computation, application, and popularization of the singularvalue decomposition of rectangular matrices. Matrix fans also probably know about Jack Dongarra's Tennessee plate, LAPACK, commemorating the popular package of linear algebra routines to which he has made many contributions. (In fact, he previously owned LAPACK in Illinois, and LINPACK in New Mexico before that.)

The most celebrated problem of theoretical computer science- "Is $P$ equal to $N P$ ?"- - should probably show up on the 
highway too. But at present nobody has voted either for $\mathrm{P} E \mathrm{Q}$ NP or for P NEQ NP, at least not in California or Massachusetts or New York or in any other state that I checked. (With two cars, you could hedge your bet and acquire both plates.)

The California list of 1981 [8] included some lowbrow computer-related examples such as A HACK, ALGOL 60, CODER, HACKERS, HACKIT, I CMPUTE, I COBOL, PC SALES; also TEXWEB, which startled me when I spotted it during a visit to Marin County in 1984. By 1986, a car bearing PC WIDOW was already on the road in the East [13].

Armando Stettner, an engineer at Digital Equipment Corporation (DEC) who was working on the UNIX ${ }^{\circledR}$ operating system, decided in 1983 to get New Hampshire license plates that said UNIX. People in those days were clamoring for software licenses that would allow them to use this proprietary system legitimately, so he convinced DEC to make mock "UNIX licenses" to be handed out at conventions. These souvenir plates became wildly popular [35].

As I was writing the present essay I happened to see the California license UPSTART, which microcomputer pioneer Lee Felsenstein has owned since he created a "startup" in 1986. I also came across TURING1, proudly driven by the Computer History Museum curator Dag Spicer. Dag told me that TURING itself was unavailable when he made his choice.

I've also heard about two clever vanity-plate ideas based on programming languages, both of which happen to be presently available in California. The first one, DO 4 TRAN, will be readily understood by any FORTRAN programmer. But the second, $4 \mathrm{TH}$ IF $\mathrm{H}$, needs a bit of explanation: It means "Honk (H) if you love Forth," in perfectly decent Forth-language syntax (when followed by THEN).

I must confess that, when I was following a car several years ago whose rear license read ENOFILE, it took me a minute to realize that the driver wasn't necessarily a programmer.

Somebody in California is now driving a car whose license reads CDR CAR. Maybe it's a man named Charles Dudley Robinson. But I hope it's actually a LISP programmer, ideally one who knows also that the left and right halves of a machine word, when LISP was first implemented on the IBM 704 computer, were obtained by the respective instructions $\mathrm{CDR}$ (contents of the decrement field of a register number) and CAR (contents of the address field of a register number).

Other plates refer to computer graphics, or to the Internet, or to user interfaces, artificial intelligence, robotics, networking, texting, etc. But that's a topic for another essay, to be published perhaps in the Information Technological Intelligencer.

\section{Other Countries}

Canada began to catch the US-style vanity plate craze in the 1980s, beginning in Ontario and Prince Edward Island, where motorists had already been allowed to choose their own standard-format letters and numbers since 1973. By 2007, about 3\% of all Canadian plates were vanitized-not counting the provinces of Quebec and Newfoundland/ Labrador, which have so far held out against such freedom of choice. (Québécois can, however, display anything they want on the fronts of their cars, because the official plates appear only in back.)

Ontario's vanity plates allow up to 8 characters, but they are subject to special restrictions in order to enhance readability by law enforcement officials [34]: The letters A, $S, G$ are respectively equivalent to the digits $4,5,6$; and $\mathrm{O}$ is equivalent to both 0 and $Q$. Thus the license 666SAGAS would preclude 255 others such as GG65A645, and $00 \mathrm{GOOGOL}$ would preclude 971 lookalikes. Furthermore, you can't have more than four equivalent characters in a row, as in GRRRRR or XXXXXXX.

Nothing like the US or Canadian freedom to vanitize is possible in England, where the number plates are subject to severe syntactical restrictions. Britishers do, however, sometimes try; for example, a popular singer named Jess Conrad reportedly once threatened a duel in Regents Park in order to acquire the plate JC21.

When Britain introduced auto registration in 1903, Bertrand Russell's older brother Frank famously waited in line all night so that his car could be identified as A1. (He later became Under-Secretary of State for Transport, responsible for abolishing British speed limits.) More recently, the comedian Jimmy Tarbuck was known for driving COM 1C; hairstylist Nicky Clarke owns H41 RD0; James Bond could be 13 OND; and a yellow Mercedes convertible supposedly says ORG 45M. Somebody claims to have reserved L1 NUX in 1993, and L7 NUX was being auctioned in 2001.

Similar remarks apply to licenses in Germany. Therefore I was astonished and thrilled when the plate

\section{IX2009}

was presented to me as a surprise gift several years ago, after I'd given some lectures about the MMIX computer [25] at the University of Applied Sciences in Munich. Indeed, the German prefix MM is available only in a small nearby village, where one of my hosts happened to have the connections necessary to acquire this miraculously perfect combination on my behalf. Notice also the elegant typography.

Vanity plates, American style, have however spread to the northern shores of Europe, beginning in Scandinavia. I think Sweden was first, in 1993 or so, followed soon after by Finland, Denmark, and Iceland. Norway will begin to issue personlige bilskilt in 2010. Meanwhile Latvia, Poland, Luxembourg, Slovenia, and even Austria have jumped on the bandwagon. Rumor has it that the Netherlands will be vanitized next. Will their plates have room for WISKUNDE?

At the opposite end of the world, "true" vanity plates do exist nowadays in Australia, New Zealand, and Hong Kong; they have also occasionally been issued in the Philippines for special events. Japanese motorists live with a rather bizarre system in which they have freedom only to choose a serial number from 1 to 9999, leading to license plates of the forms $\ldots a, \ldots a b, . a b c$, or $a b-c d$, where $a, b, c$, and $d$ are digits with $a \neq 0$. Furthermore, $c d$ is never 42 or 49 , because those numbers connote "death" or "bitter death" in Japanese. (In Japan the fact that $\varphi(49)=42$ is bad news.) Beginning in 1999, monthly lotteries were held for 
the 26 most popular numbers ...s, .sss, $s 0-00$, ss-ss, 12-34 and 56-78, where $s \in\{1,2,3,5,7,8\}$; this list was later decreased to only 13 entries. If you want one of the other values, you can pay extra to get your favorite.

On the continent of Africa one can reportedly obtain vanity plates in Liberia and Uganda. But South America is still holding out. Indeed, US-style vanity plates seem to be presently unavailable anywhere in Latin America except in Puerto Rico, where they are called tablillas especiales personalizadas.

\section{Conclusion}

We've seen that vanity-plate fever is sweeping through many parts of the world, and that this phenomenon presents remarkable challenges to mathematicians. One of the main unresolved problems is to determine the integers of 5 to 8 digits that are most "interesting," in some reasonably mathematical sense.

As I did this research I learned about six or seven available plates that would suit me well and make me happy. But unfortunately I have only one car, and I can't decide which of the plates to live without. So I guess I'll just continue to fantasize about the possibilities.

\section{ACKNOWLEDGMENTS}

The networking skills of Eugene Miya were especially helpful in bringing many choice examples to my attention, and I've also been helped by dozens of other people in casual conversations about the subject. Andrew Turnbull provided important historical information. David Bailey, Dave Bayer, Carol Bohlin, Laurence Brevard, David Eisenbud, Michel Goemans, Ron Graham, Victor Miller, Bill Ragsdale, and Cathy Seeley contributed photos. Gay Dillin of NCTM sent details of the 2005 contest. The four-author $\pi$ photograph was taken by Raul Mendez. I found the PROF SVD image on Wikimedia Commons, where it had been posted by Da Troll.

\section{OPEN ACCESS}

This article is distributed under the terms of the Creative Commons Attribution Noncommercial License which permits any noncommercial use, distribution, and reproduction in any medium, provided the original author(s) and source are credited.

\section{REFERENCES}

[1] Anonymous, "First new California plates appear," Los Angeles Times (6 December 1962), A1.

[2] Anonymous, "Playful plates: Connecticut tags identify owners," Life 31, 23 (3 December 1951), 133.

[3] D. H. Bailey, J. M. Borwein, P. B. Borwein, and S. Plouffe, "The quest for pi," The Mathematical Intelligencer 19, 1 (Winter 1997), 50-57.

[4] David Bayer and Michael Stillman, "On the complexity of computing syzygies; computational aspects of commutative algebra," J. Symbolic Comp. 6 (1988), 135-147.
[5] Fabrice Bellard, "Pi computation record," http://bellard.org/pi/pi 2700e9/announce.html [accessed January 2010].

[6] G. Boccara, "Nombre de representations d'une permutation comme produit de deux cycles de longueurs donnees," Discrete Mathematics 29 (1980), 105-134.

[7] Richard P. Brent, "Computation of the regular continued fraction for Euler's constant," Mathematics of Computation 31 (1977), $771-777$.

[8] State of California, Department of Motor Vehicles, Environmental License Plate Numbers (21 July 1981).

[9] F. R. K. Chung and R. L. Graham, "Quasi-random set systems," Journal of the Amer. Math. Soc. 4 (1991), 151-196.

[10] R. F. Churchhouse, "Covering sets and systems of congruences," in Computers in Mathematical Research, edited by R. F. Churchhouse and J.-C. Herz (Amsterdam: North-Holland, 1968), 20-36.

[11] Matt Cunningham, "A bumper crop of physics plates," Symmetry 5, 3 (August 2008), 22-27.

[12] Jean-Marie De Koninck, Those Fascinating Numbers (American Mathematical Society, 2009).

[13] Faith W. Eckler, "Vanity of vanities," Word Ways 19 (1986), 195-198; All is vanity," Word Ways 20 (1987), 141-143.

[14] Paul Erdös, "On integers of the form $2^{k}+p$ and some related problems," Summa Brasiliensis mathematicæ 2 (1950), 113-123.

[15] Michel X. Goemans and David P. Williamson, "Improved approximation algorithms for maximum cut and satisfiability problems using semidefinite programming," Journal of the ACM 42 (1995), 1115-1145.

[16] Solomon W. Golomb, "Run-length encodings," IEEE Transactions on Information Theory IT-12 (1966), 399-401.

[17] Solomon W. Golomb, Robert E. Peile, and Robert A. Scholtz, Basic Concepts in Information Theory and Coding: The Adventures of Secret Agent 00111 (New York: Plenum, 1994).

[18] Gerry Griffin, "New Hampshire license plate museum," panel 3, http://nhlpm.com/3.html [accessed November 2009]

[19] Walter Hansen, "Zum Scholz-Brauerschen Problem," Journal für die reine und angewandte Mathematik 202 (1959), 129-136.

[20] G. H. Hardy, Ramanujan: Twelve Lectures on Subjects Suggested by His Life and Work (Cambridge, England: Cambridge Univ. Press, 1940).

[21] Donald E. Knuth, Seminumerical Algorithms, Volume 2 of The Art of Computer Programming (Reading, Mass.: Addison-Wesley, 1969).

[22] Donald E. Knuth, Surreal Numbers: How Two Ex-Students Turned On to Pure Mathematics and Found Total Happiness (Reading, Mass.: Addison-Wesley, 1974).

[23] Donald E. Knuth, $\mathrm{T}_{\mathrm{E}} \mathrm{X}$ : The Program, Volume $\mathrm{B}$ of Computers \& Typesetting (Reading, Mass.: Addison-Wesley, 1986), 2. [Versions 3.14, 3.141, 3.1415, 3.14159, 3.141592, 3.1415926 were released respectively in 1991, 1992, 1993, 1995, 2002, 2008.]

[24] Donald E. Knuth, "Teach calculus with Big O," Notices of the Amer. Math. Soc. 45 (1998), 687-688.

[25] Donald E. Knuth, MMIX: A RISC Computer for the New Millennium, Volume 1, Fascicle 1 of new material for The Art of Computer Programming (Upper Saddle River, New Jersey: Addison-Wesley, 2005). 
[26] Donald E. Knuth, Combinatorial Algorithms, part 1: Volume 4A of The Art of Computer Programming (Upper Saddle River, New Jersey: Addison-Wesley, 2010).

[27] David Larsen, “Words you can't drive by," Los Angeles Times (20 January 1970), B1, B8.

[28] François Le Lionnais, Les Nombres Remarquables (Paris: Hermann, 1983).

[29] Tien-Yien Li and James A. Yorke, "Period three implies chaos," Amer. Math. Monthly 82 (1975), 985-992.

[30] Megan Luther, "'A license to make a statement, " Argus Leader (25 October 2009), appendix, http://www.argusleader.com/assets/ pdf/DF1451091023.PDF [accessed November 2009].

[31] Andy Magid, "Mathematics and the public," Notices of the Amer. Math. Soc. 51 (2004), 1181.

[32] Colman McCarthy, "A PLATE 2 CALL YOUR OWN," The Washington Post Times Herald (2 March 1969), Potomac magazine, 25-27.

[33] Pace P. Nielsen, "A covering system whose smallest modulus is 40," Journal of Number Theory 129 (2009), 640-666.

[34] Ontario Ministry of Transportation, "Personalized licence plates," http://www.mto.gov.on.ca/english/dandv/vehicle/plates.shtml [accessed November 2009].
[35] The Open Group, "The history of the UNIX ${ }^{\circledR}$ license plate," http://www.unix.org/license-plate.html [accessed November 2009].

[36] Grisha Perelman, "The entropy formula for the Ricci flow and its geometric applications," http://arxiv.org/abs/math/0211159

[37] Herbert E. Salzer, "Tables of coefficients for obtaining central differences from the derivatives," Journal of Mathematics and Physics 42 (1963), insert facing page 163.

[38] Neil J. A. Sloane, The On-Line Encyclopedia of Integer Sequences, http://oeis.org/ [accessed November 2009].

[39] Gay Talese, "State unit urges car law changes," The New York Times (16 January 1959), 12.

[40] UTAH.GOV services, "Personalized license plates," http:// dmv.utah.gov/licensepersonalized.html [Accessed November 2009].

[41] David Wells, The Penguin Dictionary of Curious and Interesting Numbers (Harmondsworth, Middlesex, England: Penguin Books, 1986).

[42] George Woltman, "Great Internet Mersenne Prime Search GIMPS," http://www.mersenne.org [accessed November 2009]. 